\title{
Passing Behavior on Rural Two-Lane Highways
}

\author{
Ayman A. Abdul-Mawjoud \\ College of Engineering \\ University of Mosul-Iraq
}

\author{
Gandhi G. Sofia \\ College of Engineering \\ University of Al-Mustansriya-Iraq
}

\begin{abstract}
Passing on rural two-lane highways is one of the most important driving tasks. More than 28000 vehicles were observed and the passing maneuvers were recorded of 10 two-lane highways in northern Iraq during June and July months of 2005. It was found that the number of passing maneuver increase as the flow rate for both directions increase up to $1500 \mathrm{veh} / \mathrm{hr}$ flow rate. The passing maneuvers decreases with the increase in flow rate. The increase in flow rate causes an increase in demand of passing and decrease in passing supply. Volume of around $212 \mathrm{veh} / \mathrm{hr}$ gives a balance between demand of passing and passing supply.
\end{abstract}

Keywords: flow rate, passing maneuvers, rural highway, two-lane highway.

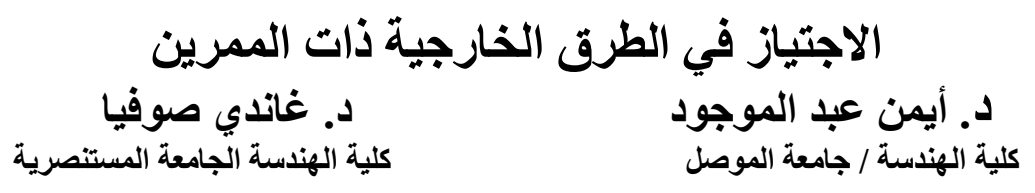

$$
\text { المستخلص }
$$

تعتبر عملية الاجتيز في الطرق الخارجية ذات الممرين واحدة من اهم مهمات قيادة المركبات. تم ملاحظة اكثر من فئن

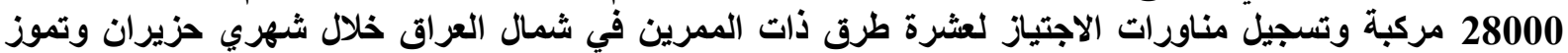

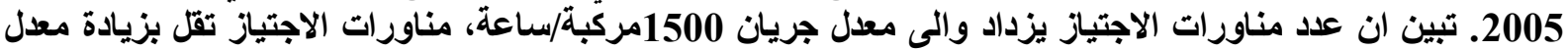

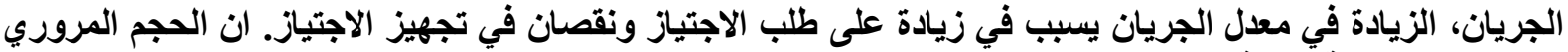
بحدود 212 مركبة/ساعة تعطي التوانن بين الطلب على الاجتياز وتجهيز الاجتياز. الكلمات الدالة: معدل الجريان، مناورة الاجتياز، الطرق الخارجية، الطرق ذات الممرين. 


\section{Introduction}

Passing on rural two-lane highways is one of the most significant yet complex and important driving tasks [1]. This process, though, is relatively difficult to quantify, primarily because of the many stages involved and the lengthy section of road that typically is needed to complete the maneuver. Road capacity, safety, and level of service are all affected by the passing ability of faster vehicles. The ability to pass is influenced by a variety of parameters including the volumes of through and opposing traffic, the speed differential between the passing and passed vehicles, the highway geometry particularly available sight distance, and human factors $[2,3,4]$.

\section{Background}

\section{Passing Mechanism}

On ordinary two-lane highways passing vehicles must use the lane reserved for oncoming traffic. Passing demands, as well as supply, occur at certain locations at certain times. Passing can occur, when passing demand and supply occur at the same time at the same location [5, 6, 7]. As a vehicle approaches a slower vehicle, it has three options [8]:

1. It can pass the slower vehicle "on the fly".

2. It can follow the slower vehicle until a passing opportunity is found.

3 . It can follow the vehicle ahead with no passing intention.

The first option is possible, if the driver finds a passing opportunity when the slower vehicle is reached. If there is no passing opportunity at that moment, the driver must wait following the slower vehicle. It is however, possible that the driver will stay as a follower because of high traffic and /or heavy vehicle flow rate, or because the speed of the vehicle ahead is only slightly slower than the desired speed of the driver. In both cases the driver considers the difference in travel time not worth the safely risk of passing. This third option is usually ignored in theoretical models. All vehicles following a vehicle with a slower desired speed are assumed to pass at the first opportunity.

If vehicles can not pass slower vehicles without delay, platoons begin to form. Platooning increases the proportion of relatively short (follower) headways and decreases the mean speed. In addition, in front of slower vehicles there are empty zones, which can not be used effectively. This reduces the capacity of two-lane highway [5].

Mahdi [9] concluded that the main two parameter, which affect the passing behavior, are the size of the accepted gap and the speed of the passed vehicle.

\section{The Passing Demand / Supply Model}

The passing demand / supply model of two-lane flow performance was proposed by Werner and Morrall [10]. The model concept is based on the premise that driver's perception of level of service is determined by his ability to pass slower moving vehicles. Therefore, flow performance as perceived by drivers will depend on the demand for passing in the primary stream and the supply of passing opportunities provided by the sight distance profile and gaps in the opposing stream $[8,11]$.

Before a driver will pass, the passing opportunity must be greater than some minimum value. This minimum passing opportunity is termed a critical gap. For simplicity it usually assumed in traffic engineering studies that each driver has a single constant critical gap [9]. Observed variation in gap acceptance is; therefore, attributed entirely to differences between drivers. 
Dommerholt and Botma [2, 12] assumed that the average driver needs headway of 20 sec in the opposing flow to carry out a passing. This is a crude representation of average driver behavior and no dependence on speed is taken into account.

Polus et al. [13] found that the accepted gap while passing ranged approximately from 9 to $23 \mathrm{sec}$, the median being about $16 \mathrm{sec}$.

McLean [11] stated that Normann in 1942 found the following linear model for the ratio of supply to demand passing:

$P=0.903-0.000467 \mathrm{Q}$

Where, $\mathrm{Q}$ is the total two-way flow rate. The number of supply (observed) passing becomes zero as flow rate reaches $1934 \mathrm{veh} / \mathrm{hr}$. It should be noted that the data of Normann shows considerable scatter and an apparent non-linear effect.

Morrall [14] showed that the models based on passing supply and demand provide a better representation of driver's perceptions of quality of service than traditional measures based on volume/ capacity ratios.

\section{Objective of the Study}

The goals of this study were to:

1- Find the relation between passing maneuvers and flow rate for each and both directions.

2- Find the relation of demand of passing and passing supply with traffic flow.

\section{Data Collection Methodology}

The types of sites that were selected included site with high to moderate traffic volumes located in both level and rolling terrain with sufficient sight distance. A total of 10 field sites in three governorates in northern Iraq i.e., Mosul, Erbil and Dohuk were selected in this study. Data collection was carried during June and July months of 2005.

Two video cameras were placed and played on the roadside at each end of the roadway section. Measurements were carried out simultaneously at both lanes. Marking were fixed at each end of section and served as reference points for measurement. Vehicle license numbers and type together with the time of passage were manually transferred into computer files.

The length of the observed section was not less than $3.0 \mathrm{~km}$, as proposed by 2000 edition of the Highway Capacity Manual [15]. Cameras were hidden from the view of the driver because it may influence their driving behavior. The record section was focused in the field of the camera and traffic was recorded for more than 3 hours for each site during peak periods on a typical weekday.

The recorded film was played on a monitor screen to extract the traffic information's. More than 28000 vehicles were observed and their traffic characteristics recorded. For each of passage of a vehicle, the following data were conducted: vehicle license number, type of vehicle, arrival and departure time to the section.

The traffic characteristics, vehicle characteristics and operational performance measures that were determined directly or indirectly in the field studies include:

-Flow rate derived for 15-minute intervals.

-Vehicle types i.e. passenger car or truck.

-Headways between successive vehicle. 
-Numbers and types of passing and passed vehicles.

The components of passing maneuver were evaluated on the basis of real passing for which data were collected for about 6800 passing on two-lane rural highways. The passes were not observed directly, but obtained through the difference in entry and exit orders at both ends of road test sections. If the order at the end differs from the order at the beginning, vehicles have performed an overtaking maneuver. The method is precisely described in Hegeman [16].

\section{Analysis and Results}

\section{Types of Passing and Passed Vehicles}

Two types of vehicles are considered in this study i.e., passenger car and truck. Table (1) shows the percentage of truck in passing and passed vehicles. It is shown from the table that the ranges of percentages of truck in passing and passed vehicles are 4 to 11 and 47 to 68 respectively. The difference in the range depended on the characteristics of highways and vehicles.

Table (1): Percentage of Truck in Passing and Passed Vehicles

\begin{tabular}{|c|c|c|c|}
\hline Highway & $\begin{array}{c}\text { \%of truck in } \\
\text { flow rate }\end{array}$ & $\begin{array}{c}\text { \%oof truck in } \\
\text { passing vehicle }\end{array}$ & $\begin{array}{c}\text { \%of truck in } \\
\text { passed vehicle }\end{array}$ \\
\hline Mosul - Kirkuk & 20 & 11.3 & 47.4 \\
\hline Mosul - Bashaka & 6 & 8.7 & 58.1 \\
\hline Mosul - Rabiya & 12 & 6.6 & 56.3 \\
\hline Mosul - Talafir & 18 & 8.1 & 54.8 \\
\hline Mosul - Sahage & 14 & 3.8 & 68.6 \\
\hline Erbil - Kirkuk & 12 & 10.6 & 56.1 \\
\hline Erbil - Sulyminya & 9 & 8.1 & 60.5 \\
\hline Erbil - Salahaldin & 9.5 & 9.3 & 58.5 \\
\hline Dohuk - Mosul & 28 & 9.8 & 53.4 \\
\hline Dohuk - Zawita & 1.5 & 4.2 & 55.4 \\
\hline
\end{tabular}

\section{Passing and Headway}

Vehicles that pass the one that preceded it at entry of studied sections are considered to be contiguous vehicle. However, accumulative percentage of contiguous vehicle with headway for Mosul - Sahage highway as an example is shown in Figure (1). The general form of the equation is:

Accumulative $\%$ of contiguous vehicle $=a+b \ln ($ headway $)$ 


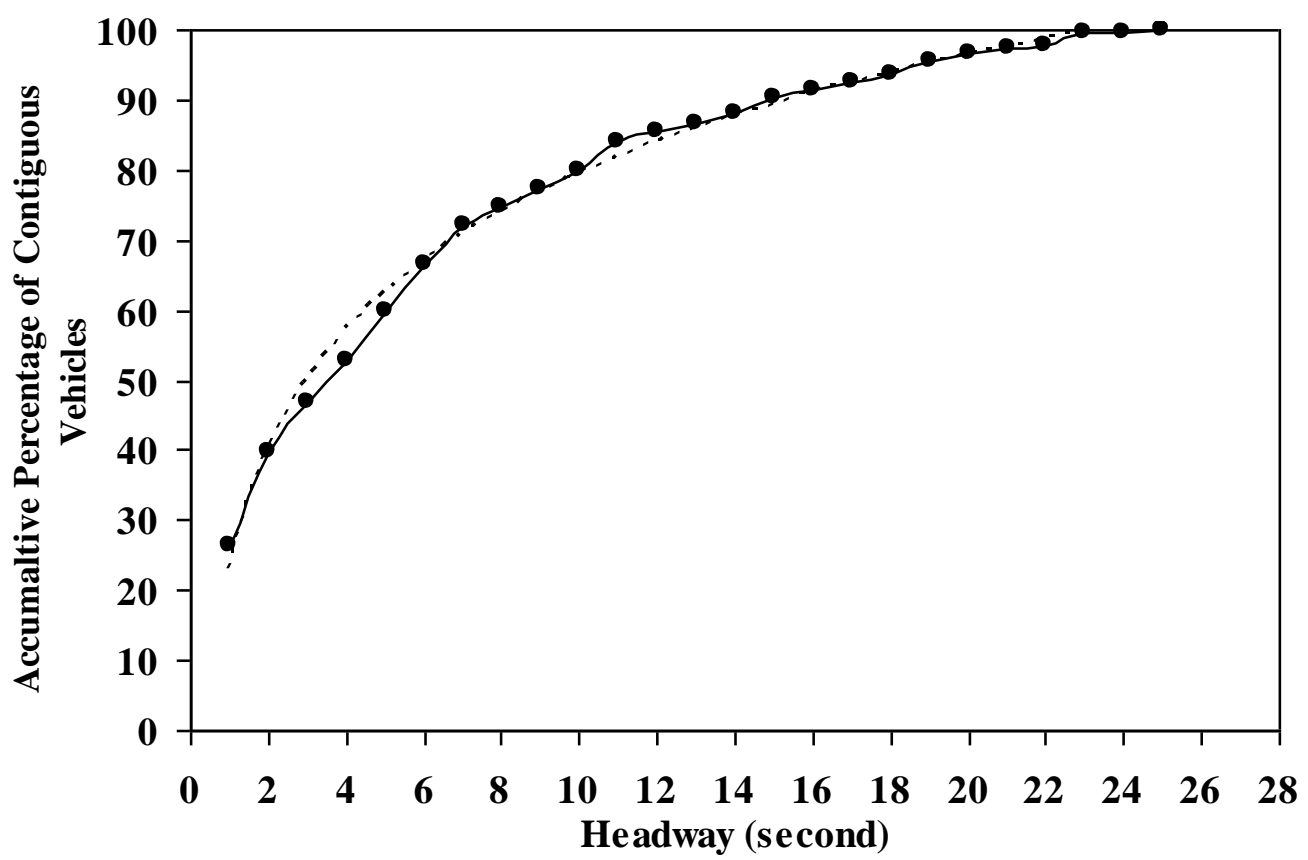

Figure (1): Accumulative Percentages of Contiguous Vehicles with Headway, Mosul - Sahage Highway

The values of the parameters (a) and (b) are shown in Table (2).

Table (2): Regression Parameters for Accumulative Percentage of Contiguous Vehicle

\begin{tabular}{|l|c|c|c|}
\hline \multicolumn{1}{|c|}{ Highway } & a & b & $\mathbf{R}^{\mathbf{2}}$ \\
\hline Mosul - Kirkuk & 40.728 & 19.676 & 0.98 \\
\hline Mosul - Bashaka & 35.297 & 20.418 & 0.99 \\
\hline Mosul - Rabiya & 41.704 & 19.088 & 0.94 \\
\hline Mosul - Talafir & 38.857 & 19.933 & 0.95 \\
\hline Mosul - Sahage & 22.997 & 24.478 & 0.99 \\
\hline Erbil - Kirkuk & 45.527 & 18.573 & 0.99 \\
\hline Erbil - Sulyminya & 30.425 & 23.053 & 0.99 \\
\hline Erbil - Salahaldin & 36.119 & 20.956 & 0.97 \\
\hline Dohuk - Mosul & 36.009 & 20.778 & 0.96 \\
\hline Dohuk - Zawita & 69.148 & 11.195 & 0.89 \\
\hline
\end{tabular}

\section{Passing and Flow Rate}

Number of passing maneuvers increase in the highway as the flow rate for both directions increase as shown in Figure (2). However, for high flow rate (greater than 1500 $\mathrm{veh} / \mathrm{h}$ ) the number of passing maneuvers was decreased as flow rate increased (as shown for Dohuk - Zawita highway). Possible explanations for this difference are:

-Drivers didn't expect to gain much travel time by passing on these busy highways sections and even stick to this tendency when volumes are not extreme;

-Drivers postpone their passing to nearby highway sections where the opportunities are greater. However, a linear relationship was found between number of passing $(\mathrm{veh} / \mathrm{h} / \mathrm{km})$ and flow rate $(\mathrm{V})$, as the following formula: 
number of passing maneuvers $=\mathrm{a}+\mathrm{b}(\mathrm{V})$

The values of parameters (a) and (b) for the highways under study are shown in Table (3).

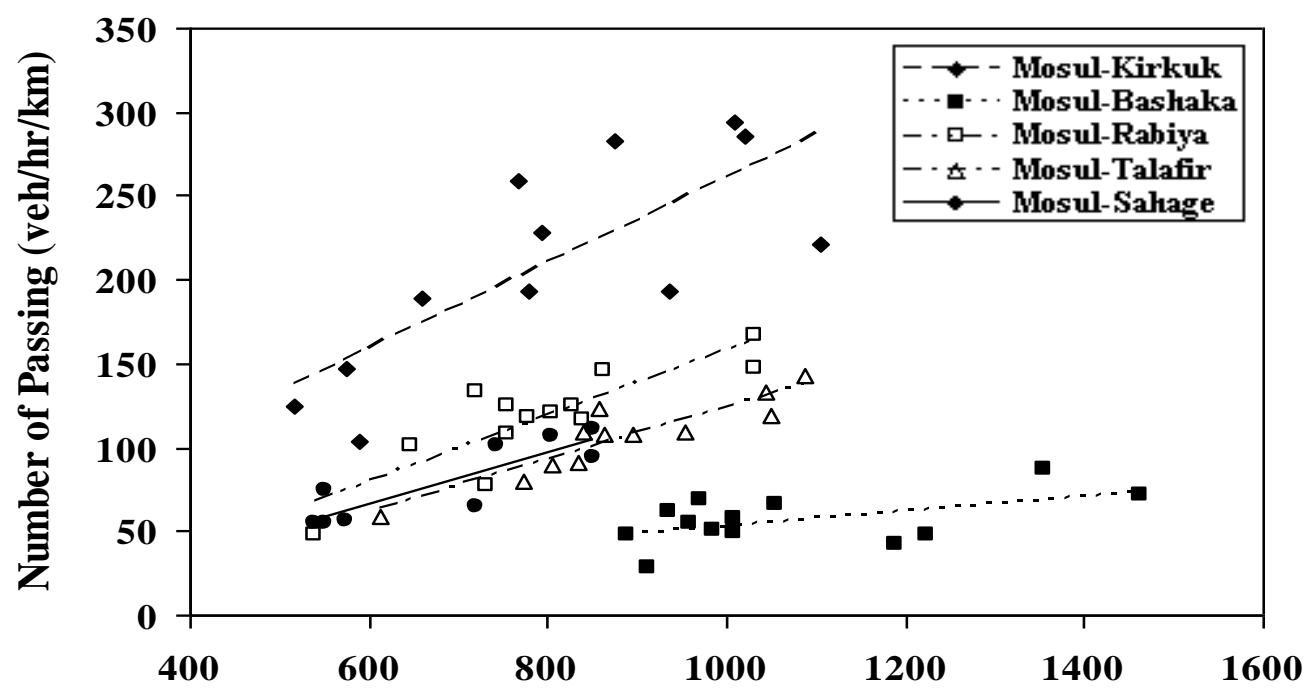

Flow Rate in both Direction (veh/h)

(a) Mosul Highways

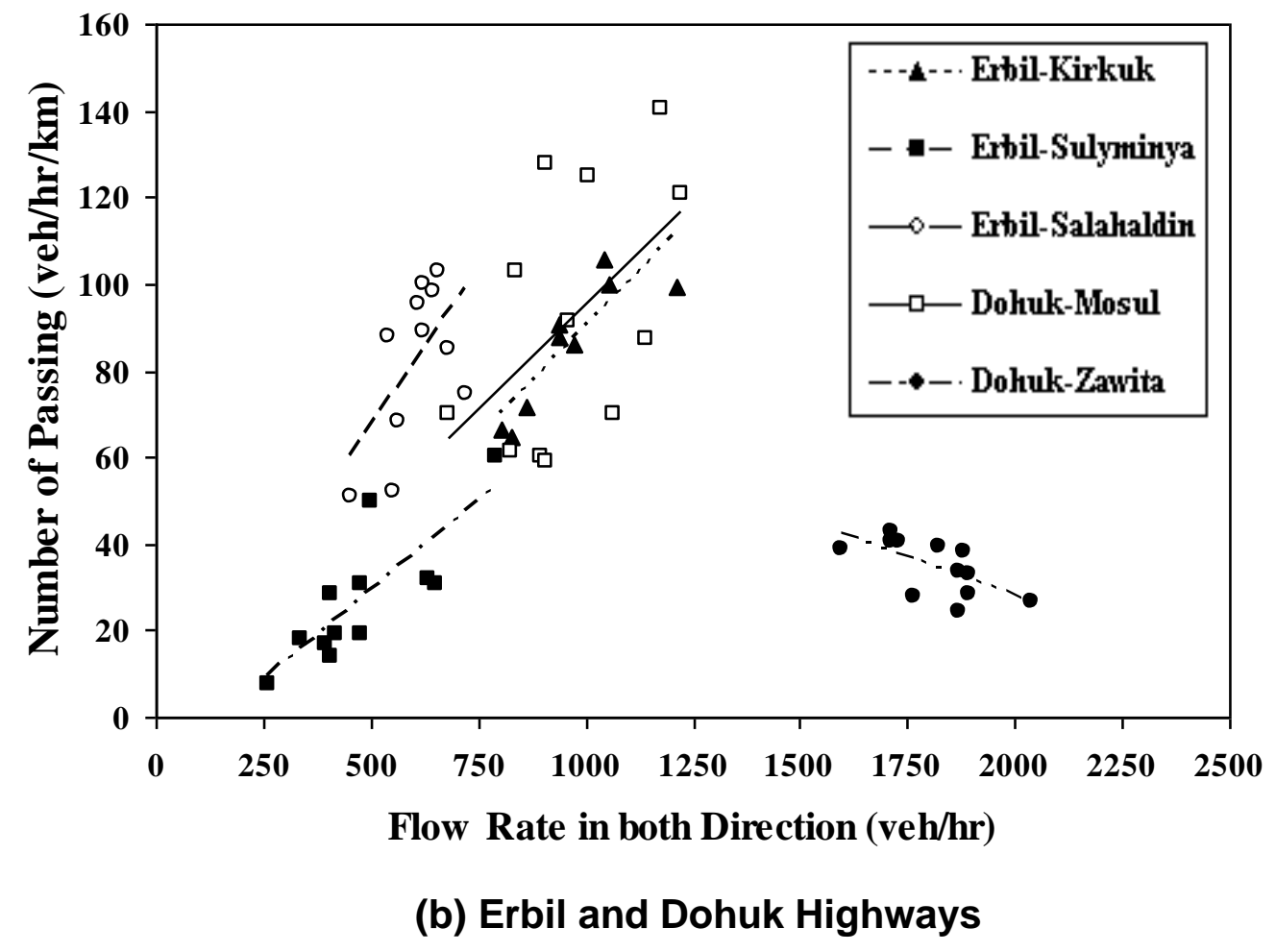

Figure (2): Number of Passing against Flow Rate in both Directions 
Table (3) Regression Parameters for Relation between Passing and Flow Rate

\begin{tabular}{|l|c|c|c|}
\hline \multicolumn{1}{|c|}{ Highway } & a & b & $\mathbf{R}^{2}$ \\
\hline Mosul - Kirkuk & 5.932 & 0.255 & 0.59 \\
\hline Mosul - Bashaka & 8.791 & 0.044 & 0.48 \\
\hline Mosul - Rabiya & -37.699 & 0.195 & 0.73 \\
\hline Mosul - Talafir & -33.832 & 0.158 & 0.82 \\
\hline Mosul - Sahage & -25.228 & 0.152 & 0.75 \\
\hline Erbil - Kirkuk & -12.306 & 0.102 & 0.75 \\
\hline Erbil - Sulyminya & -12.837 & 0.083 & 0.67 \\
\hline Erbil - Salahaldin & -6.939 & 0.147 & 0.35 \\
\hline Dohuk - Mosul & -1.460 & 0.097 & 0.27 \\
\hline Dohuk - Zawita & 97.096 & -0.035 & 0.41 \\
\hline
\end{tabular}

When the flow rate is considered as a directional $\left(\mathrm{V}_{\mathrm{d}}\right)$ and opposing flow rate $\left(\mathrm{V}_{\mathrm{o}}\right)$, the number of passing increase with the increase of flow rate for the same direction and with decrease of flow rate on the opposing direction. The following results were obtained:

Number of passing maneuvers $=\mathrm{a}+\mathrm{b}\left(\mathrm{V}_{\mathrm{d}}\right)+\mathrm{c}\left(\mathrm{V}_{\mathrm{o}}\right)$

Table (4) shows the values of the parameters. While Figure (3) shows the reduction in number of passing with the increase of flow rate in opposing direction. Therefore, it was shown that there is more demand for passing in heavier flow and more opportunities to pass due to less to opposing vehicles. The opposite is true for the lighter flow in other direction.

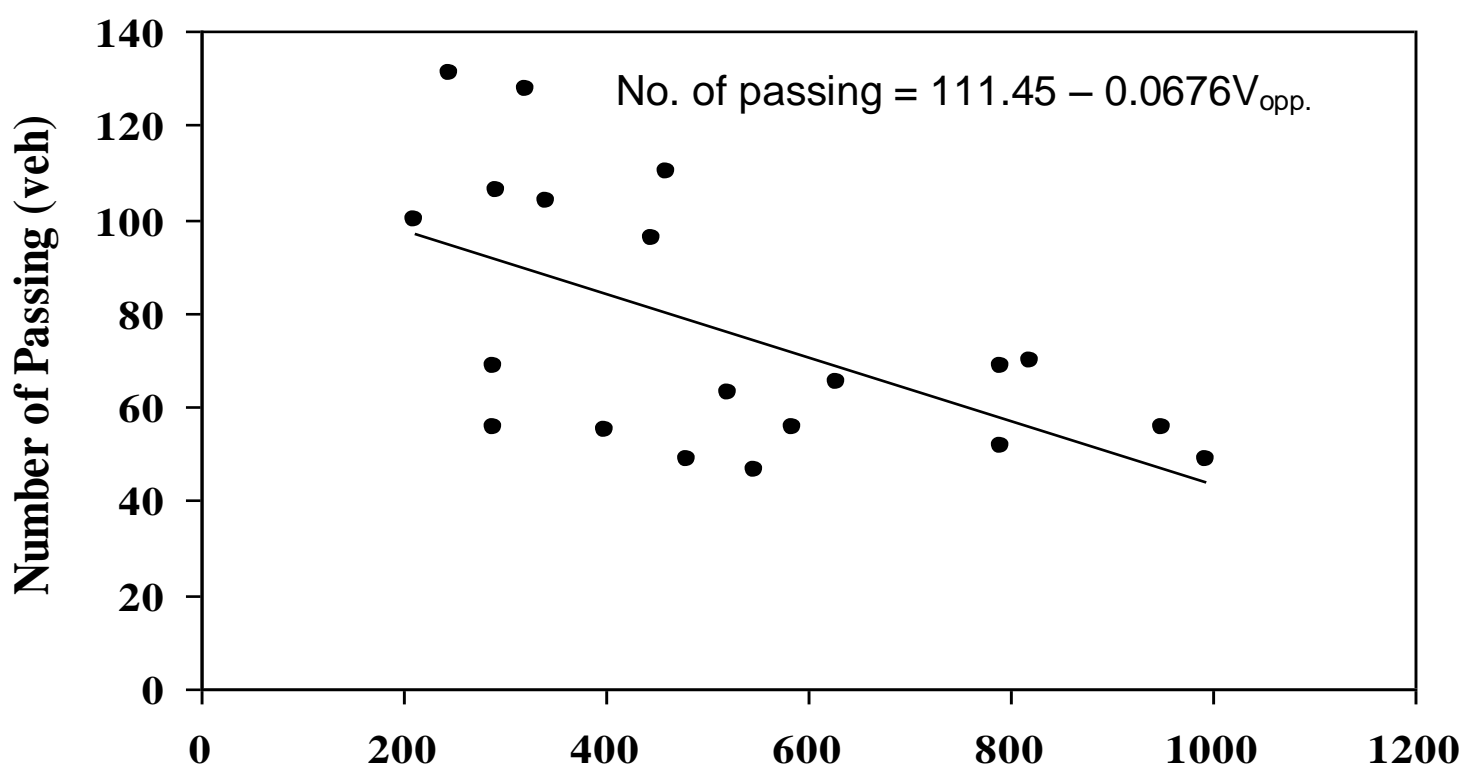

Opposing Traffic Volume (pc/h)

Figure (3):Total Number of Passing against Opposing Flow for all sights 
Table (4): Regression Parameters for Relation between Passing and both Directional and Opposing Flow Rate

\begin{tabular}{|l|c|c|c|c|}
\hline \multicolumn{1}{|c|}{ Highway } & a & b & c & $\mathbf{R}^{2}$ \\
\hline Mosul - Kirkuk & -6.441 & 0.328 & -0.044 & 0.59 \\
\hline Mosul - Bashaka & -5.437 & 0.188 & -0.034 & 0.68 \\
\hline Mosul - Rabiya & -6.408 & 0.354 & -0.082 & 0.81 \\
\hline Mosul - Talafir & -1.461 & 0.316 & -0.089 & 0.72 \\
\hline Mosul - Sahage & -26.338 & 0.279 & -0.021 & 0.76 \\
\hline Erbil - Kirkuk & -2.370 & 0.189 & -0.054 & 0.64 \\
\hline Erbil - Sulyminya & -10.297 & 0.186 & -0.042 & 0.73 \\
\hline Erbil - Salahaldin & -21.583 & 0.225 & -0.014 & 0.73 \\
\hline Dohuk - Mosul & 3.487 & 0.277 & -0.096 & 0.63 \\
\hline Dohuk - Zawita & -10.326 & 0.118 & -0.035 & 0.84 \\
\hline
\end{tabular}

The number of passing vehicles and the traffic volume are observed for all sites, in each and both directions. Numbers of passing are collected per 15 minutes and aggregated to hourly values per $\mathrm{km}$ and also per $\mathrm{km}$ per 100 vehicles. Figure (4) shows the relationships between total passing and traffic volumes. It is shown from the figure that beyond the value of $650 \mathrm{pc} / \mathrm{h}$ for each direction, and $1200 \mathrm{pc} / \mathrm{h}$ for both directions, total passing is reduced. It seems that drivers don't want to carry out a passing when their desired speed is only marginally more than the speed of the platoon in which they drive. With the increasing volume, the vehicles that do not pass increase and this may be because drivers are not inclined to take the trouble to pass, while they are expect that they will face the next platoon within a short time.

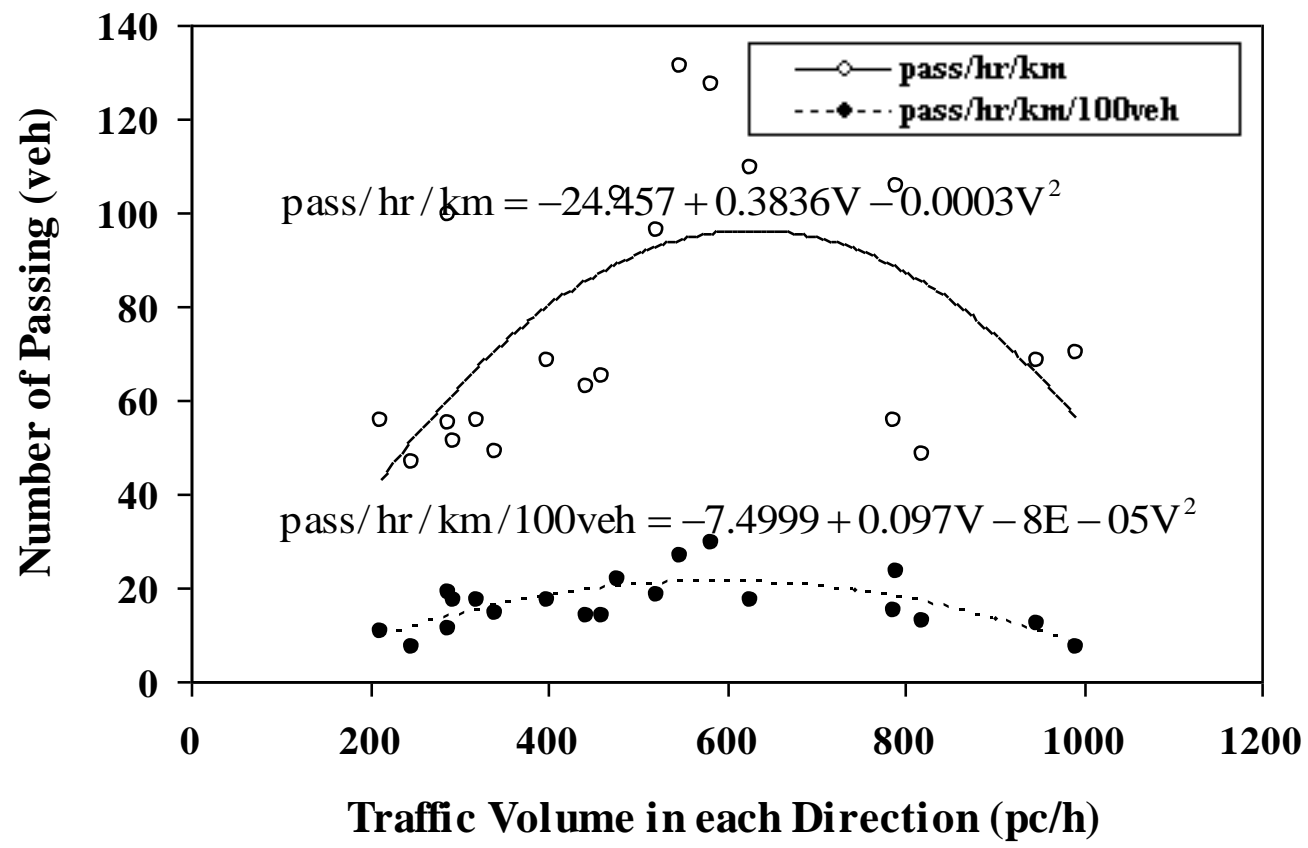

(a) Each Direction 
Abdul-Mawjoud: Passing Behavior on Rural Two-Lane Highways

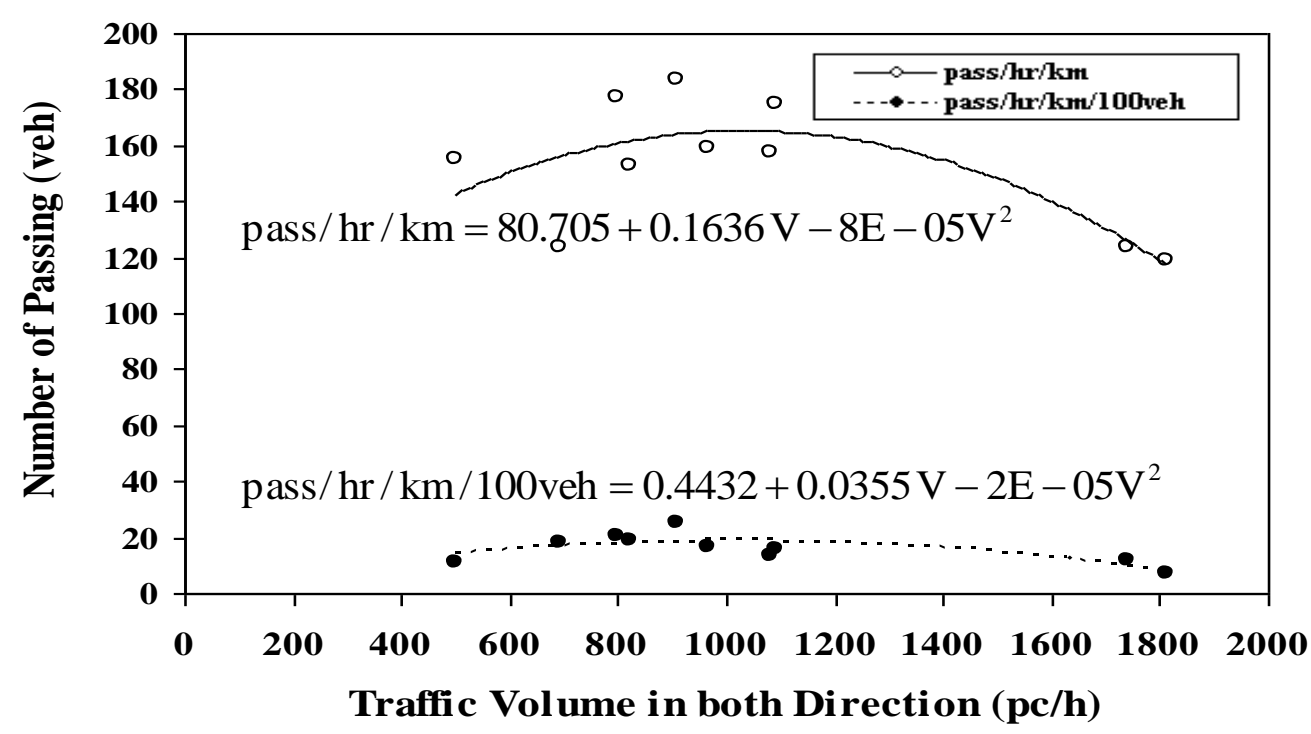

(b) Both Directions

\section{Figure (4): Total Number of Passing with Traffic Volume} for each and both Directions

\section{Effect of Gaps for Passing}

The headways between vehicles are depending on flow rate on that lane. Passing on two-way two-lane depend mainly on gaps between oncoming vehicles in opposing lane. The minimum critical gaps that were assumed to be constant and suitable for reasonably safe passing was 15 second as proposed by Polus et al., [13] for level terrain. However, when the volume of oncoming traffic in the opposing lane $(\mathrm{V})$ increases the percentage headway greater than or equal to 15 second $(\% \mathrm{H} \geq 15 \mathrm{sec})$ decreases as shown in Figure (5). Therefore, when the opposing percentage headway greater than or equal to 15 second $\left(\% \mathrm{H}_{\mathrm{opp}} \geq 15 \mathrm{sec}\right)$ increases, the opportunity of passing increases, as shown in Figure (6).

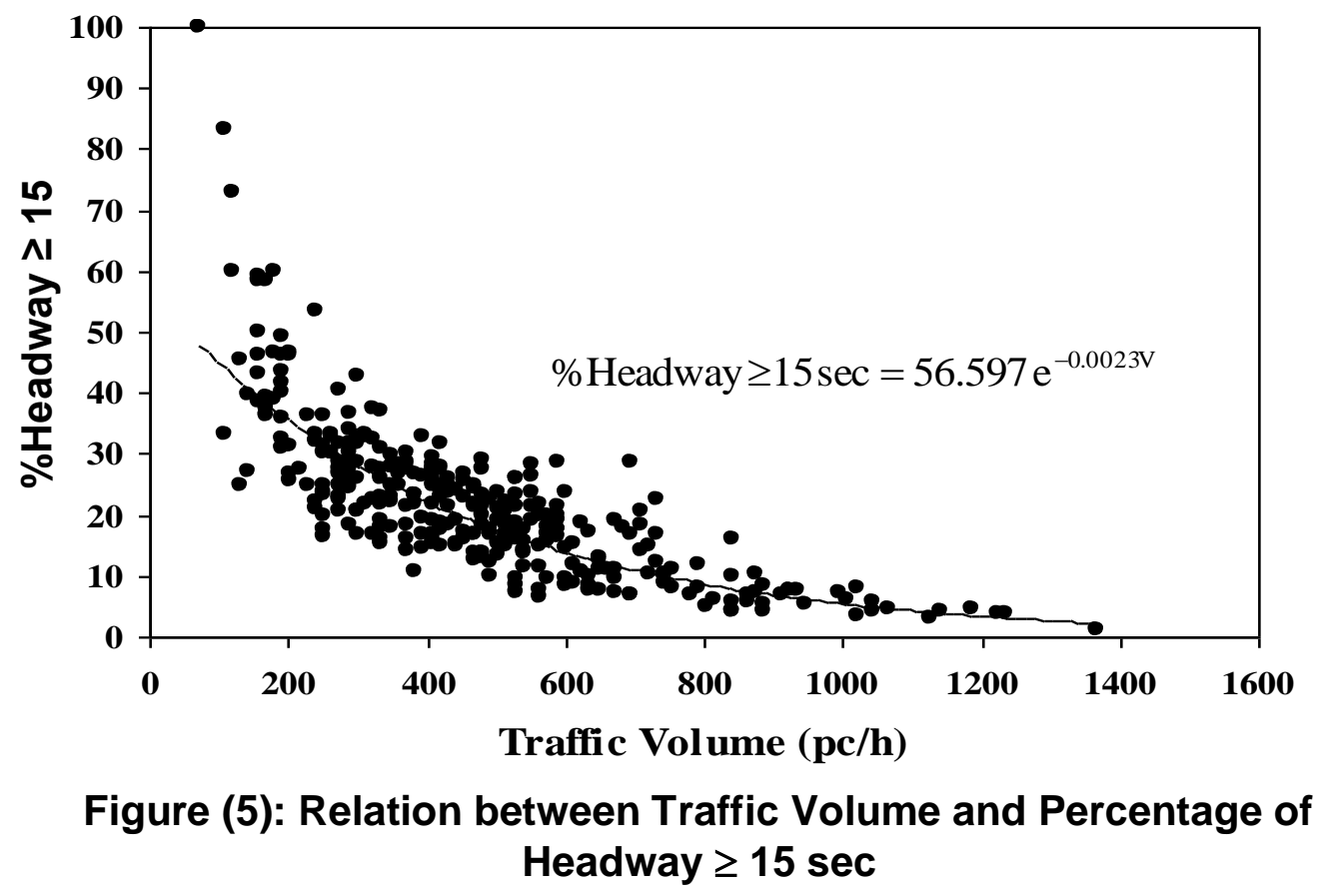




\section{Passing Demand versus Passing Supply}

A vehicle is considered to have a demand for passing that had headway less than or equal to 3 second with a vehicle ahead. While passing supply are a number of gaps in oncoming vehicle in the opposing direction which is sufficient to complete passing. A gap of 15 second or more is considered to be sufficient to complete passing. However, demand of passing increased with increase in flow rate. While passing supply increased with a decrease in flow rate in opposing direction. Platoon will form when the demand for passing is greater than passing supply.

A plot of demand of passing and passing supply for all highways in this study is shown in Figure (7). The point of intersection between the two lines gives a balance volume of around $212 \mathrm{veh} / \mathrm{h}$. It means that if the volume is greater than $212 \mathrm{veh} / \mathrm{h}$, the demand of passing is greater than passing supply and the reverse is true.

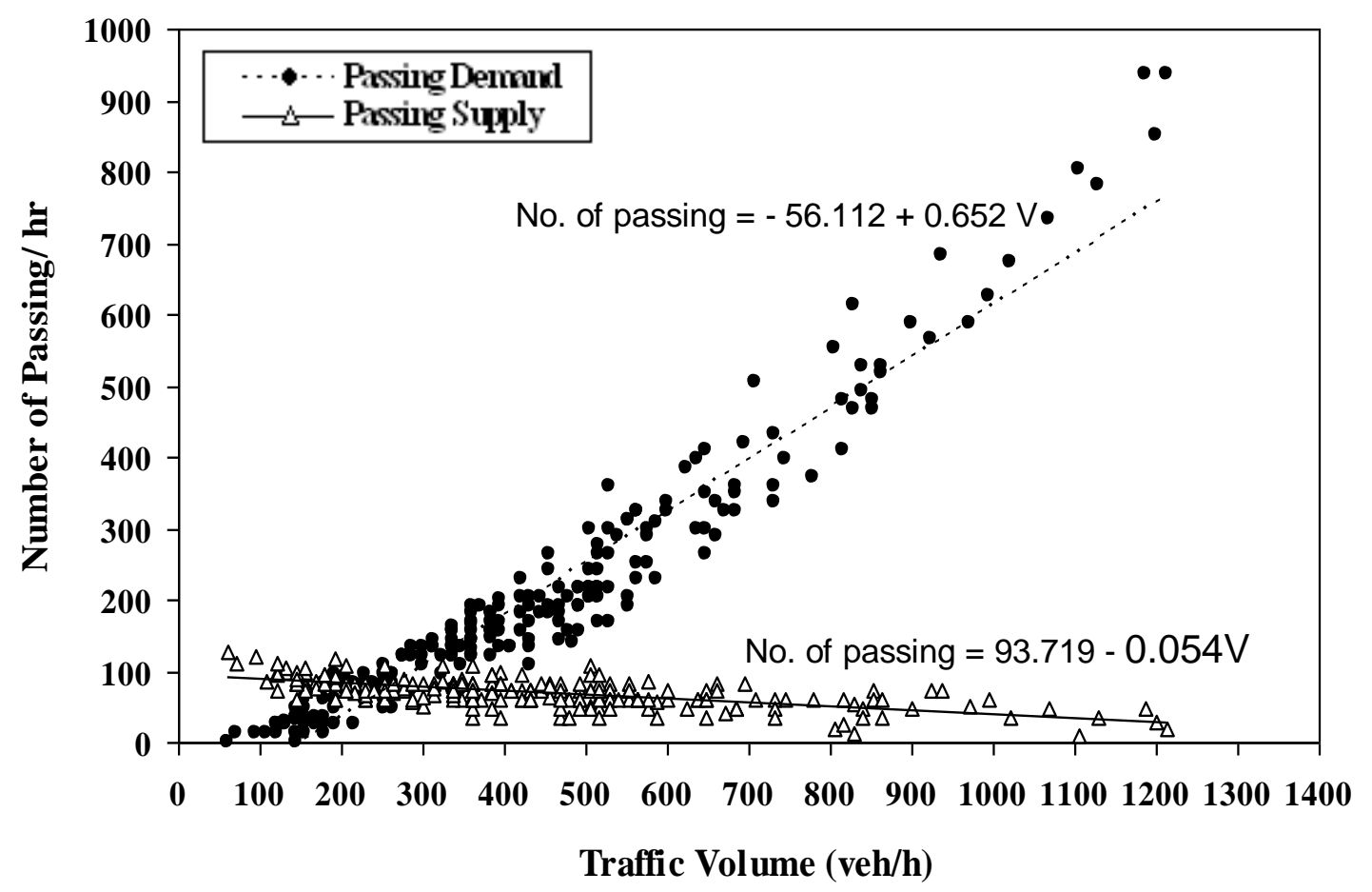

Figure (7): Passing Demand and Supply on all Two-Lane Highways

\section{Observed Passing/ Passing Demand}

The ratio of observed passing over demand passing is the actual passing divided by the number of vehicles with headway less than or equal to 3 seconds.

The ratio was plotted against traffic volume for both directions as shown in Figure (8). It is shown form the figure that as traffic volume increased the ratio is decreased, this is because both of the increase in demand and decrease in observed passing.

A linear regression analysis yielded the following relations:

$\mathrm{P}=0.845-0.4 \mathrm{Q}$

Where,

P: ratio of observed to demand passing.

Q: total traffic flow $\left(10^{3} \mathrm{veh} / \mathrm{h}\right)$. 
The number of observed passing becomes zero as flow rate reaches $2110 \mathrm{veh} / \mathrm{h}$.

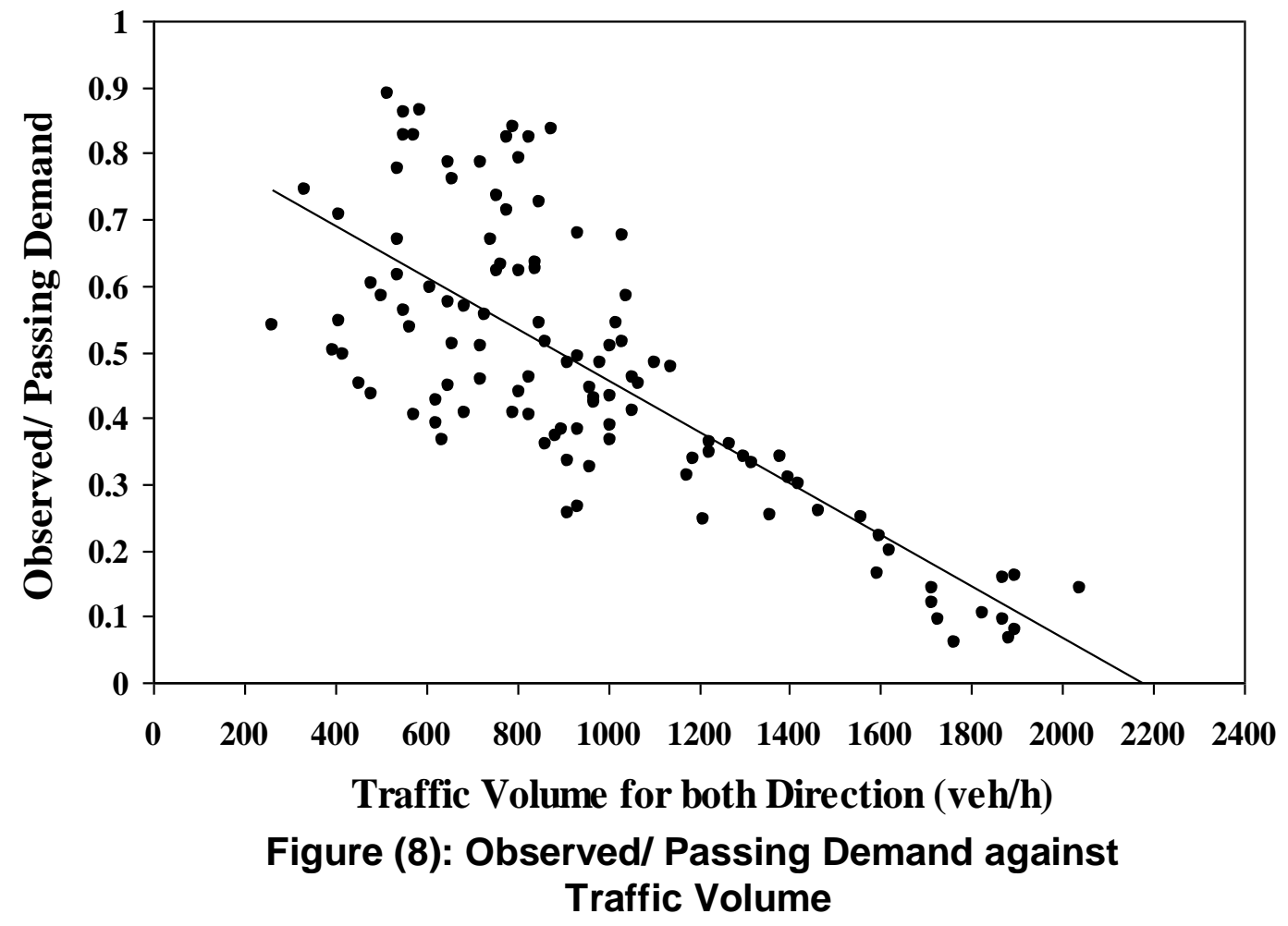

\section{Conclusions and Recommendations}

Within the limitations of studied sites, the conclusions drawn from the analysis of the data are described below:

1- The ranges of percentages of truck in passing vehicles is 4 to 11 , while for passed vehicles is 47 to 68 .

2- Number of passing maneuvers increase as the flow rate for both directions increase up to $1500 \mathrm{veh} / \mathrm{hr}$ flow rate. For flow rate greater than $1500 \mathrm{veh} / \mathrm{hr}$, the number of passing maneuvers was decrease as flow rate increase.

3- Number of passing maneuvers increase with the increase of flow rate for the same direction and with decrease of flow rate on the opposing direction.

4- Demand of passing increased with increase of flow rate. While passing supply increased with a decrease in flow rate in opposing direction. Volume of around $212 \mathrm{veh} / \mathrm{hr}$ gives a balance between demand of passing and passing supply.

5 - The ratio of observed over demand of passing decreased with the increase of traffic volume for both directions. The number of observed passing becomes zero as flow rate reaches 2110 $\mathrm{veh} / \mathrm{hr}$.

It is recommended to study passing maneuvers at different oncoming gaps. 


\section{References}

1.Hoban, C. J., "Towards a Review of the Concept of Level of Service for Two-Lane Rural Roads". Australian Road Research, Volume, 13, No. 3, 1983.

2.Botma, H., "Traffic Operation on Busy Two-Lane Rural Road in the Netherlands". Transportation Research Record No. 1091, Transportation Research Board, Washington, D. C., 1986.

3.Taylor, M. A. P., Miller A. J., and Ogden K. W., "A Comparison of some Bunching Models for Rural Traffic Flow". Transportation Research, Volume 8, Issue 1, February, 1974.

4.Daganzo, C. F., "Probabilistic Structure of Two-Lane Road Traffic". Transportation Research, Volume 9, Issue 6, 1975.

5.Luttinen, R. T., "Level of Service on Finish Two-Lane Highways". Fourth International Symposium on Highway Capacity Proceedings, Transportation Research Circular E-C018, Transportation Research Board, Washington, D. C. 2000.

6.Alexander, H. B., and Pisano, P. A., "An Investigation of Passing Accidents on Two-Lane, Two-Way Roads". Public Roads, Volume 56, Issue 2, September 1992.

7.Romana, M. G., "Passing Activity on Two-Lane Highways in Spain". Transportation Research Record No. 1678. Transportation Research Board, Washington, D. C., 1999.

8.Luttinen, R. T. "Traffic Flow on Two-Lane Highways-An Overview". TL Research Report 1/2001, TL Consulting Engineers, Ltd., Lahti, 2001.

9.Mahdi, T. A., "The Effect of Overtaking Provision on the Operating Characteristics of Single Carriageway Roads". Ph. D. Dissertation, School of Engineering, University of Wales, Cardiff, Wales, 1991.

10.Werner, A. and Morral, J. F., "Unified Traffic Flow Theory Model for Two-Lane Rural Highways". Transportation Forum, Volumes, 1-3, 1984.

11.McLean, J. R., "Two-Lane Highway Traffic Operations - Theory and Practice”. Gordon and Breach Science Publisher New York, 1989.

12.Dommerholt, W., and Botma, H., "Model to Determine Operating Quality on Two-Lane Rural Roads". Paper Presented at ITE 58 ${ }^{\text {th }}$ Annual Meeting, Vancouver, Canada, 1988.

13.Polus, A., Livneh, M. and Frisher, B., "Passing Behavior on Two-Lane Rural Highways". Transportation Research Record No. 1701, Transportation Research Board, Washington, D. C., 2000.

14.Morall, J. F., "Impact of Passing Lane on the Quality of Service on Two-Lane Highways". Proceeding of the Third International Symposium on Highway Capacity, Copenhagen, 1998. 15.Highway Research Board 2000, Highway Capacity Manual, Washington, D. C., 2000. 16.Hegeman, G., "Overtaking Frequency on Two-Lane Rural Roads". Safety Possibilities of ADAS, TRAIL Congress, Rotterdam, 2004. 